TITLE:

\title{
Primate models of interference control
}

$\operatorname{AUTHOR}(S)$ :

Watanabe, Kei; Funahashi, Shintaro

CITATION:

Watanabe, Kei ...[et al]. Primate models of interference control. Current Opinion in Behavioral Sciences 2015, 1: 9-16

ISSUE DATE:

2015-02

URL:

http://hdl.handle.net/2433/207709

\section{RIGHT:}

(C) 2014. This manuscript version is made available under the CC-BY-NC-ND 4.0 license http://creativecommons.org/licenses/by-nc-nd/4.0/.; この論文は出版社版でありません 。引用の際には出版社版をご確認ご利用ください。; This is not the published version.

Please cite only the published version. 
Highlights

1. Interference control is an ability to protect ongoing cognitive processing from distractors.

2. Dual-task paradigms provide important information to elucidate the flexible allocation of cognitive resource for interference control.

3. Animal studies using the dual task help to understand the neural mechanisms of interference control. 


\title{
Primate models of interference control
}

\author{
Kei Watanabe $e^{1,2,3}$ and Shintaro Funahashi ${ }^{2 \dagger}$
}

1. Department of Experimental Psychology, University of Oxford, OXI 3UD, UK

2. Kokoro Research Center, Kyoto University, Kyoto, 606-8501, Japan

3. Japan Society for the Promotion of Science (JSPS), Tokyo, 102-8472, Japan

$\dagger$ Correspondence

Shintaro Funahashi, Ph.D.

Professor

Kokoro Research Center

Kyoto University

46 Yoshida-Shimoadachi, Sakyo-ku,

Kyoto, 606-8501, Japan

Phone \& Fax: (+81) 75-753-9674

E-mail: funahashi.shintaro.2z@kyoto-u.ac.jp 


\begin{abstract}
Interference control is the ability to protect ongoing cognitive processing from internal or environmental distraction. For an individual to achieve interference control appropriately, either a control mechanism to coordinate multiple processing streams, such as the central executive in working memory, a mechanism to flexibly allocate the cognitive resource with a limited capacity for performing each task, or both, are needed. Through the use of dual-task paradigms, animal studies have provided important information to elucidate the neural mechanisms of the central executive and the flexible allocation of cognitive resource. These animal studies should help to promote our understanding of the neural mechanisms of interference control.
\end{abstract}




\section{Introduction}

Interference control, which is the ability to protect ongoing cognitive processing from internal or environmental distraction, has long been a subject of interest in cognitive psychology. The ability to achieve interference control is strongly correlated with the performance of higher-order cognitive functions such as language comprehension, problem-solving, and fluid intelligence. Human cognition studies have focused on inhibition-related functions [1-3], and dual-task paradigms have been used to investigate the mechanisms that underlie interference control. The general principle of the dual-task paradigm is for subjects to perform two relatively complex tasks simultaneously, each of which includes a distinct goal and stimulus-response association. Despite the remarkable flexibility of cognitive abilities, human subjects often exhibit decreased performance in either or both component tasks of the dual-task paradigm, since information processing for one task interferes with the other [4]. The addition of a more cognitively demanding secondary task can strongly disrupt performance of the primary task. Since heavy cognitive demands on the information processing system are thought to produce dual-task interference, either a control mechanism to coordinate multiple processing streams, such as the central executive in working memory model $[5,6]$, or a control mechanism to flexibly allocate cognitive resource for each task $[7,8]$, is required in addition to the control process for each component task. Recent behavioral studies have indicated that humans and animals exhibit a similar dual-task interference effect. Therefore, animal studies may be able to provide valuable insight to understand the neural mechanisms of interference control. This review focuses on the results obtained using dual-task paradigms and explains how animal studies help to elucidate the neural mechanisms of interference control.

\section{Behavioral analyses of the dual-task interference effect in animals}


Behavioral analyses of the interference effect in dual-task conditions have been conducted in studies using animals (Table 1). Although these experiments were conducted under dual-task conditions, some examined the functional similarity of short-term memory (STM) processes between humans and animals, rather than the psychological mechanisms related to dual-task interference. In humans, rehearsal is negatively affected when a secondary task is introduced during the retention period of the primary STM task. Therefore, if the STM is a functionally equivalent process in humans and animals, a similar negative effect on the rehearsal process would be expected in behavioral performance of dual tasks in animals.

Moise [9] examined this issue using monkeys. In the dual-task, a reaction time (RT) task was repeatedly inserted during the retention interval $(<30 \mathrm{~s})$ of a delayed matching-to-sample (DMS) task. In the RT task, monkeys were required to quickly touch an illuminated cue. The rationale was that, if the monkey's maintenance of memoranda relied on effortful rehearsal processes, the introduction of RT trials during the retention period should disrupt the performance of the DMS task, since effort was required to perform RT trials. In fact, DMS performance was markedly disrupted by the insertion of RT trials to a degree proportional to the number of inserted RT trials. The author concluded that the performance in both the DMS and RT required some degree of active processing which taxed a common capacity-limited cognitive resource, and that the nature of memory maintenance in DMS performance in monkeys was reminiscent of active rehearsal in human STM.

On the other hand, Washburn and Astur [10] also investigated whether or not monkeys could rehearse visual short-term memoranda. They inserted two secondary tasks during a variable retention interval $(<48 \mathrm{sec})$ in the DMS task. The secondary task was either manual tracking of a moving circle or judgment of the number ' 2 '. Insertion of these secondary tasks disrupted the performance of the DMS task. However, manual 
tracking produced no more disruptive effects than passive viewing of a moving circle, and the response times in the numerical judgment task were comparable during a retention interval and an intertrial interval of the DMS task. Therefore, the authors concluded that monkeys did not rely on active rehearsal processes to maintain memoranda.

Although contradictory results have been obtained from experiments that examined the cross-species similarity of STM, these studies showed that, with the addition of relatively simple secondary tasks, a dual-task interference effect can be observed in monkeys. Subsequent studies demonstrated that not only monkeys $[11,12]$ but also pigeons [13,14] and rats [15-19] can also perform dual-tasks in various conditions and also exhibit dual-task interference effects analogous to those in humans (Table 1). Recently, Smith et al. [12] applied the dual-task method to examine whether or not metacognitive process can be dissociated from perceptual-level process using monkeys. In the dual-task condition, a metacognitive task was inserted during the retention period of a DMS task or a STM task. The metacognitive task included a sparse-middle-dense discrimination of random dots and the 'uncertain' response when the monkey was difficult to discriminate. As a result, a dual-task interference effect was observed. In addition, they found that the number of 'uncertain' responses dramatically decreased in the dual-task condition, while the performance of the sparse-middle-dense discrimination was not affected. These results indicate that the dual-task method can dissociate a lower level perceptual process from a higher level decisional process, such as metacognition. Thus, the dual-task paradigm is useful not only for examining the mechanism of interference control but also for examining other higher cognitive functions such as metacognition.

The load-dependent effect of dual-task interference is an important characteristic of human dual-task performance [20,21] and an important phenomenon to 
examine the mechanism of interference control. Basile and Hampton [11] showed that this effect was also evident in monkey dual-task performance. In their study, a DMS task was coupled with one of four secondary tasks that required different levels of cognitive demand (Figure 1a): (1) no secondary task, (2) a motor-only task, in which monkeys needed to touch a blue square presented at the screen corner, (3) an image perception task, in which monkeys needed to touch an unclassifiable complex image, and (4) a classification task, in which monkeys needed to classify an image as a bird, fish, flower, or person. Either four images (small set) or 1400 images (large set) were used as target images in the DMS task. In the small-set condition, due to the frequent appearance of the same images across trials, a target image would be hard to distinguish from distractors based solely on familiarity during the memory test. In contrast, the cognitive effort was less demanding in the large-set condition, since the infrequent appearance of a target image made it easier to distinguish it from distractors based on familiarity. The critical finding was that the addition of the secondary task impaired DMS performance only in the small-set condition in a load-dependent manner (Figure 1b). This result indicates that the short-term maintenance of familiar information requires an active resource-demanding process similar to the human rehearsal process. This result also indicates that the additive effect of the magnitude of DMS performance deficits is strongly similar to the dual-task interference effect in humans. Thus, these findings validate the effectiveness of the use of primate models to investigate the neural mechanisms that underlie human dual-task interference effects. Similar additive effects were also observed in rats $[17,18]$ and pigeons [13]. The similarity of the dual-task interference effects in humans and animals suggests the presence of common cognitive processes related to dual-task interference. This could make it possible to apply a variety of neurobiological techniques to nonhuman primates to investigate the neural mechanisms related to dual-task interference effects. 


\section{Neural mechanisms of dual-task interference effects in monkeys}

fMRI studies have shown that the lateral prefrontal cortex (LPFC) is involved in dual-task interference effects [3,22-26]. The precise roles of the LPFC in dual-task interference effects and their neural mechanisms remain largely unknown [22, 27]. However, since the cognitive capacity limitations in humans and monkeys have similar characteristics [28,29], it is expected that a common neural mechanism for the flexible allocation of cognitive resource is present in both humans and monkeys while they perform dual tasks. Therefore, neurophysiological studies using monkeys could provide some important evidence for understanding the neural mechanisms of dual-task interference.

Single-neuron recordings from monkeys performing dual tasks are beginning to reveal the neural mechanisms responsible for dual-task interference [30-33] (Table 1). In the monkey's lateral prefrontal cortex (LPFC), Wise and colleagues [30, 31] examined the neural mechanisms related to interference effects using a dual-task-like paradigm (Figure 2a). In their task, while monkeys looked at a fixation point at the center of a screen, a visual cue was first presented at one position and then revolved around the fixation point to a second position. The brightness of the visual cue then either increased or decreased after the end of the delay period $(1.0-2.5 \mathrm{sec})$, and this informed the monkeys to make a saccade to the first or second position, respectively. Therefore, monkeys were required to attend to the visual cue at the second position to detect the change in brightness while remembering the fist position during the delay period. The authors found 'specialized' neurons that encoded either the remembered or attended position (Figure 2b). They also found a substantial number of 'multi-tasking' neurons that encoded both the remembered and attended positions (Figure 2c). Multi-tasking neurons exhibited several computational advantages over specialized 
neurons in resolving dual-task interference effects. For example, multi-tasking neurons encoded different (often diametrically opposite) positions for both attention and memory and exhibited stronger spatial tunings than specialized neurons, thereby representing a larger amount of information than specialized neurons (Figure 2d). These results suggest that the activities of multi-tasking neurons in the LPFC may constitute an important part of neural processes related to dual-task interference.

Recently, Watanabe and Funahashi [33] investigated the neural mechanism of dual-task interference in the monkey LPFC using a dual task that consisted of a spatial memory task [34] and a spatial attention task [35] with a varying load (Figure 3a). In this experiment, monkeys were required to remember the location of a visual cue to make a saccade in the later memory test (memory task component). At the same time, they were also required to attend to a location where a small circle was presented on the monitor to perform quick lever-release when they detected that the color of the circle had changed (attention task component). The difficulty of the attention task was parametrically manipulated by varying the location of the to-be-attended circle (Figure 3b). The rationale of the experiment was that, if LPFC neurons participate in the processing of dual-task interference, delay-period activity, which was thought to represent information regarding the visual cue for the memory task [36,37], would be affected depending on the difficulty of performing the concurrent attention task.

Behavioral performance of the memory task was impaired to a degree proportional to the difficulty of performing the concurrent attention task (Figure 3c). Analyses of LPFC neuron activities showed that both the memory and attention tasks recruited the same neural population in the LPFC that participated in spatial information processing. Specifically, sustained delay-period activities that encoded the location of the visual cue for the memory task were significantly attenuated by concurrent performance of the attention task, and a more difficult attention task produced a more 
severe attenuation in delay-period activity (Figure 3d). These results demonstrate that the neural locus of dual-task interference resides in the competitive overloaded recruitment of the neural population that participates in similar information processing by two concurrently performed tasks, as has been postulated in human neuroimaging studies [23,38]. These findings also indicate that the psychological concept of processing resources [7,8] could be implemented in the brain as the limited information-processing capacity of single neurons in the LPFC.

A series of single-neuron recording experiments have shown that the representation of perceptual distractors was significantly suppressed in the LPFC [39], thereby protecting the sustained representation of behaviorally relevant information throughout the distractor-filled delay period [40, 41]. However, the characteristics of LPFC activities observed in the dual-task conditions were different than the characteristics of those elicited by the presentation of perceptual distractors. Therefore, although the LPFC plays a critical role in the processing of both perceptual $[42,43]$ and dual-task interference $[22,44]$, these two processes may depend on distinct neural circuitries. Future investigation is needed to directly compare these two neural processes using behavioral tasks that employ the same sensory stimuli in both perceptual and interference conditions.

Analyses of neural activities at the end of the secondary task showed another important facet of interference effects in the LPFC. Watanabe and Funahashi [33] found a significant 'reawakening' of neural encoding for the visual cue location in the memory task after the end of the attention task (Figure 3e), which indicates that even under the presence of the interference effect caused by the attention task, some neural mechanisms in the LPFC could operate to compensate for the interference effect produced by the attention task. Similar results have been reported by Miyazaki et al. [32], who compared the activities of LPFC neurons and dorsal premotor neurons while 
monkeys performed a dual task, which consisted of memory-guided bimanual actions (primary task) and visually-guided bimanual actions (secondary task). The observed post-interference reactivation of the primary-task information showed that the LPFC played an important role in exerting compensatory control over the interference by the secondary task. Flexible prioritization among multiple streams of concurrent task processing is critical for the coordination of dual-task performance. The observed reactivation may correspond to the neural implementation of adaptive task coordination in the LPFC $[22,24]$.

\section{Conclusions}

Behavioral analyses and physiological investigations of dual-task interference using monkeys are beginning to provide evidence regarding the neural mechanisms for interference control. The similarity of the behavioral patterns caused by dual-task interference in humans and monkeys and the capability to elucidate the fine details of neural computations by neurophysiological methods support the view that the primate model is an appropriate method for understanding the details of the neural mechanisms of the interference control and the flexible allocation of cognitive recourse.

\section{Conflict of interest statement}

Nothing declared.

\section{Acknowledgments}

This work was supported in part by Grant-in-Aids for Scientific Research (Nos. 21240024 and 25240021) from the Japanese Ministry of Education, Culture, Sports, 
Science and Technology (MEXT) to SF and by Research Fellowships for Young Scientists from the Japan Society for the Promotion of Science to KW. 


\section{References}

1. Friedman NP, Miyake A: The relations among inhibition and interference control functions: a latent-variable analysis. J Exp Psychol Gen 2004, 133: 101-135.

2. Nee DE, Jonides J: Dissociable interference-control processes in perception and memory. Psychol Sci 2008, 19: 490-500.

3. Forstmann BU, van den Wildenberg WPM, Ridderinkhof KR: Neural mechanisms, temporal dynamics, and individual differences in interference control. $J \operatorname{Cog} n$ Neurosci 2008, 20: 1854-1865.

4. - Pashler H: Dual-task interference in simple tasks: data and theory. Psychol Bull 1994, 116: 220-244.

The concept, theories, and mechanisms of the dual-task interference are discussed.

5. Baddeley A, Hitch GJ: Working memory. In The Psychology of Learning and Motivation, vol. 8. Edited by Bower GH. New York; Academic Press: 1974.

6. - Baddeley A: Working memory: looking back and looking forward. Nature Rev Neurosci 2003, 4: 829-839.

Baddeley's explanation of his most recent model of working memory.

7. Kahneman D: Attention and Effort. Englewood Cliffs, NJ: Prentice Hall; 1973.

8. Wickens CD: Multiple resources and performance prediction. Theor Issues Ergon 2002, 3: 159-177.

9. Moise SL: Short-term retention in Macaca speciosa following interpolated activity during delayed matching from sample. J Comp Physiol Psychol 1970, 73: 506-514. 
10. Washburn DA, Astur RS: Nonverbal working memory of humans and monkeys: Rehearsal in the sketchpad? Mem Cognit 1998, 26: 277-286.

11. Basile BM, Hampton RR: Dissociation of active working memory and passive recognition in rhesus monkeys. Cognition 2013, 126: 391-396.

This study demonstrated a load-dependent effect of the dual-task interference in monkeys. An additive effect of the primary- and secondary-task loads on the magnitude of the deficits in the primary task performance provides similarity in the dual-task performance in humans.

12. Smith JD, Coutinho MV, Church BA, Beran MJ: Executive-attentional uncertainty responses by rhesus macaques (Macaca mulatta). J Exp Psychol: Gen 2013, 142: 458-475.

13. Kendrick DF, Rilling $M$ : The role of interpolated stimuli in the retroactive interference of pigeon short-term memory. Anim Learn Behav 1984, 12: $391-401$.

14. Calder A, White KG: In search of consolidation of short-term memory in nonhuman animals. Learn Behav 2014, 42: 83-92.

15. Maki WS, Brokofsky S, Berg B: (1979). Spatial memory in rats: Resistance to retroactive interference. Anim Learn Behav 1979, 7: 25-30.

16. Beatty WW, Shavalia DA: Rat spatial memory: Resistance to retroactive interference at long retention intervals. Anim Learn Behav 1980, 8: 550-552.

17. Roberts WA: Retroactive inhibition in rat spatial memory. Anim Learn Behav 1981, 9: 566-574.

18. Cook RG, Brown MF: Retroactive interference in rat radial maze performance: The role of point of delay interpolation and the similarity and amount of interpolated material. Anim Learn Behav 1985, 13: 116-120. 
19. Jarrard LE, Elmes DG: Role of retroactive interference in the spatial memory of normal rats and rats with hippocampal lesions. J Comp Physiol Psychol 1982, 96: $699-711$.

20. Logie RH, Zucco GM, Baddeley $\mathrm{AD}$ : Interference with visual short-term memory. Acta Psychol 1990, 75: 55-74.

21. Strayer DL, Johnston WA: Driven to distraction: dual-task studies of simulated driving and conversing on a cellular telephone. Psychol Sci 2001, 12: 462-466.

22. D'Esposito M, Detre JA, Alsop DC, Shin RK, Atlas S, Grossman M: The neural basis of the central executive system of working memory. Nature 1995, 378: 279-281.

23. Klingberg T: Concurrent performance of two working memory tasks: potential mechanisms of interference. Cereb Cortex 1998, 8: 593-601.

24. Koechlin E, Basso G, Pietrini P, Panzer S, Grafman J: The role of the anterior prefrontal cortex in human cognition. Nature 1999, 399: 148-151.

25. Adcock RA, Constable RT, Gore JC, Goldman-Rakic PS: Functional neuroanatomy of executive processes involved in dual-task performance. Proc Natl Acad Sci USA 2000, 97: 3567-3572.

26. Derrfuss J, Brass M, von Cramon DY: Cognitive control in the posterior frontolateral cortex: evidence from common activations in task coordination, interference control, and working memory. Neuroimage 2004, 23: 604-612.

27. Klingberg T, Roland PE: Interference between two concurrent tasks is associated with activation of overlapping fields in the cortex. Brain Res Cogn Brain Res 1997, 6: 1-8.

28. Buschman TJ, Siegel M, Roy JE, Miller EK: Neural substrates of cognitive capacity limitations. Proc Natl Acad Sci USA 2011, 108: 11252-11255.

29. Elmore LC, Ma WJ, Magnotti JF, Leising KJ, Passaro AD, Katz JS, Wright AA: 
Visual short-term memory compared in rhesus monkeys and humans. Curr Biol 2011, 21: 975-979.

30. Lebedev MA, Messinger A, Kralik JD, Wise SP: Representation of attended versus remembered locations in prefrontal cortex. PLoS Biol 2004, 2: e365.

31. - Messinger A, Lebedev MA, Kralik JD, Wise SP: Multitasking of attention and memory functions in the primate prefrontal cortex. J Neurosci 2009, 29: $5640-5653$.

The authors describe 'multi-tasking' neurons in the prefrontal cortex that encode both attending as well as memorizing spatial positions in a dual-task situation. This finding provides some insight regarding how prefrontal neurons process an emergent demand for information processing with excessive capacity, like under the dual-task condition.

32. Miyazaki A, Nakajima $T$, Shima $K$, Mushiake $H$ : Neuronal activity in the prefrontal cortex during performance of a dual task consisting of a main- and an interrupting-task. In Advances in Cognitive Neurodynamics (III). Edited by Yamaguchi Y., Springer Netherlands; 2013: 795-801.

33. • Watanabe K, Funahashi S: Neural mechanisms of dual-task interference and cognitive capacity limitation in the prefrontal cortex. Nat Neurosci 2014, 17 : $601-611$

This study describes the neuronal adverse effects uniquely associated with the addition of secondary-task demands in monkey lateral prefrontal cortex. The authors provide direct neurophysiological evidences for the mechanisms that underlie behavioral performance deficits in dual-task situations. This study also demonstrates that the neural implementation of the cognitive resources, the hypothetical constructs in cognitive psychology to explain the dual-task interference effect, can be studied at the level of single-neuron activity by using nonhuman primates. 
34. Funahashi S, Bruce CJ, Goldman-Rakic PS: Mnemonic coding of visual space in the monkey's dorsolateral prefrontal cortex. J Neurophysiol 1989, 61: 331-349.

35. Kadohisa M, Petrov P, Stokes M, Sigala N, Buckley M, Gaffan D, Kusunoki M, Duncan J: Dynamic construction of a coherent attentional state in a prefrontal cell population. Neuron 2013, 80: 235-246.

36. Fuster JM: Unit activity in prefrontal cortex during delayed-response performance: neural correlates of transient memory. J Neurophysiol 1973, 36: $61-78$

37. Funahashi S, Kubota K: Working memory and prefrontal cortex. Neurosci Res 1994, 21: 1-11.

38. Passingham RE: Attention to action. Philos Trans R Soc Lond, B, Biol Sci 1996, 351: $1473-1479$.

39. Suzuki M, Gottlieb J: Distinct neural mechanisms of distractor suppression in the frontal and parietal lobe. Nat Neurosci 2013, 16: 98-104.

40. Miller EK, Erickson CA, Desimone R: Neural mechanisms of visual working memory in prefrontal cortex of the macaque. J Neurosci 1996, 16: 5154-5167.

41. Qi X, Katsuki F, Meyer T, Rawley JB, Zhou X, Douglas KL, Constantinidis C: Comparison of neural activity related to working memory in primate dorsolateral prefrontal and posterior parietal cortex. Front Syst Neurosci 2010, 4: 12, 1-11.

42. Malmo RB: Interference factors in delayed response in monkeys after removal of frontal lobes. J Neurophysiol 1942, 5: 295-308.

43. Chao LL, Knight RT: Human prefrontal lesions increase distractibility to irrelevant sensory inputs. Neuroreport 1995, 6: 1605-1610.

44. Baddeley A, Della Sala S, Papagno C, Spinnler H: Dual-task performance in 
dysexecutive and nondysexecutive patients with a frontal lesion. Neuropsychology 1997, 11: 187-194.

45. Harper DN, McLean AP, Dalrymple-Alford JC: List item memory in rats: Effects of delay and delay task. J Exp Psychol: Anim Behav Process 1993, 19: 307-316. 
Table 1. Animal studies using dual-task paradigms

\begin{tabular}{|c|c|c|}
\hline & Species & Combination of tasks \\
\hline \multicolumn{3}{|l|}{ Behavioral studies } \\
\hline Moise [9] & Monke & $\mathrm{DMS}^{\mathrm{a}}+$ simple reaction time task \\
\hline Washburn and Astur [10] & $\begin{array}{l}\text { y } \\
\text { Monke } \\
\text { y }\end{array}$ & $\mathrm{DMS}+$ overt $\mathrm{OT}^{\mathrm{b}}$ or numerical judgment task \\
\hline Basile and Hampton [11] & $\begin{array}{l}\text { Monke } \\
\mathrm{y}\end{array}$ & $\begin{array}{l}\text { DMS + motor, image perception, or image } \\
\text { classification task }\end{array}$ \\
\hline Smith et al. [12] & $\begin{array}{l}\text { Monke } \\
\mathrm{y}\end{array}$ & DMS or $\mathrm{DMP}^{\mathrm{c}}+$ perceptual confidence judgment \\
\hline Kendrick and Rilling [13] & Pigeon & $\mathrm{DMS}+\mathrm{VI}^{\mathrm{d}}, \mathrm{EXT}^{\mathrm{e}}$, or DRO ${ }^{\mathrm{f}}$ schedule \\
\hline Calder and White $[\mathbf{1 4}]$ & Pigeon & DMS + VI schedule \\
\hline Maki et al. [15] & Rat & 8-arm $\mathrm{WS}^{\mathrm{g}}$ radial maze +4 -arm $\mathrm{WS}^{\mathrm{h}}$ radial maze \\
\hline Beatty and Shavalia $[\mathbf{1 6}]$ & Rat & 8-arm WS radial maze +8 -arm WS or WS radial maze \\
\hline Roberts [17] & Rat & 8-arm WS radial maze +8 -arm WS radial maze \\
\hline Cook and Brown [18] & Rat & 12-arm WS radial maze +12 -arm WS radial maze \\
\hline Jarrard and Elmes [19] & Rat & 12-arm WS radial maze + 4-arm WS radial maze \\
\hline Harper et al. [45] & Rat & $\mathrm{SPR}^{\mathrm{i}}$ in 12 -arm maze + food consumption \\
\hline \multicolumn{3}{|l|}{ Neurophysiological studies } \\
\hline Lebedev et al. [30] & Monkey & memory-guided saccade + luminance discrimination \\
\hline Messinger et al. [31] & Monkey & memory-guided saccade + luminance discrimination \\
\hline Miyazaki et al. [32] & Monkey & memory-guided + visually-guided bimanual motor task. \\
\hline $\begin{array}{l}\text { Watanabe and Funahashi } \\
\text { [33] }\end{array}$ & Monkey & $\mathrm{DMP}+$ spatial attention task \\
\hline
\end{tabular}

${ }^{\mathrm{a}} \mathrm{DMS}=$ delayed matching-to-sample task

${ }^{\mathrm{b}} \mathrm{OT}=$ object tracking task

${ }^{\mathrm{c}} \mathrm{DMP}=$ delayed matching-to-place task

${ }^{\mathrm{d}} \mathrm{VI}=$ variable interval

${ }^{\mathrm{e}} \mathrm{EXT}=$ extinction

${ }^{\mathrm{f}} \mathrm{DRO}=$ differential reinforcement of other behavior

${ }^{\mathrm{g}}$ In the WS (delayed spatial win-shift) radial maze task, animals are required to retain spatial information for visited arms both during task performance and across a delay. Optimal behavior consisits of visiting each arm without repetition.

${ }^{\mathrm{h}} \mathrm{WS}=$ spatial win-shift task 
${ }^{\mathrm{i}} \mathrm{SPR}=$ serial probe recognition task 


\section{Figure legends}

Figure 1: Load dependency of the dual-task interference effect in monkeys. (a) The DMS task was performed concurrently with one of four kinds of secondary tasks. None, no secondary task; Motor, the motor-only task; Image, the image perception task; Classify, the classification task. (b) DMS performance in a small-set condition (red dashed line) was impaired in a load-dependent manner by adding secondary tasks, while no deficit was observed in a large-set condition (black solid line). The horizontal dashed line indicates chance level performance.

Figure 2: Prefrontal activities in dual-task-like situations. (a) A schematic diagram of the behavioral task. (b) Two examples of 'specialized' neurons that encoded either the attended (top) or remembered (bottom) location during the delay period. Polar plots illustrate spatial tunings of activities for attended (blue line) and remembered (red line) locations. (c) An example of 'multi-tasking' neurons that encoded both the attended and remembered locations with opposite spatial tunings. (d) Comparison of the coding efficiency between 'specialized' and 'multi-tasking' neurons. Decoding accuracy was always better when activities of 'multi-tasking' neurons were used.

Figure 3: Neural effects of the dual-task interference in monkey prefrontal cortex. (a) A schematic diagram of the dual task used in this study. (b) The memory task was performed simultaneously with one of five conditions of the attention task that were associated with different levels of the cognitive load. (c) The performance of the memory task was impaired by the addition of the attention task in a load-dependent manner. (d) Population averaged delay-period activity in six task conditions associated with different levels of the cognitive load. Sustained delay-period activity was 
significantly attenuated under the dual-task condition in a load-dependent manner. (e) Temporal changes of population-averaged neural signals representing the information of the attention cue (magenta), the memory cue (blue), and their interaction (green). Significant reawakening of the PEV representing the information of the memory cue was observed after the end of the attention task. PEV, proportion of explained variance. 


\section{Conflict of interest statement}

Nothing declared. 

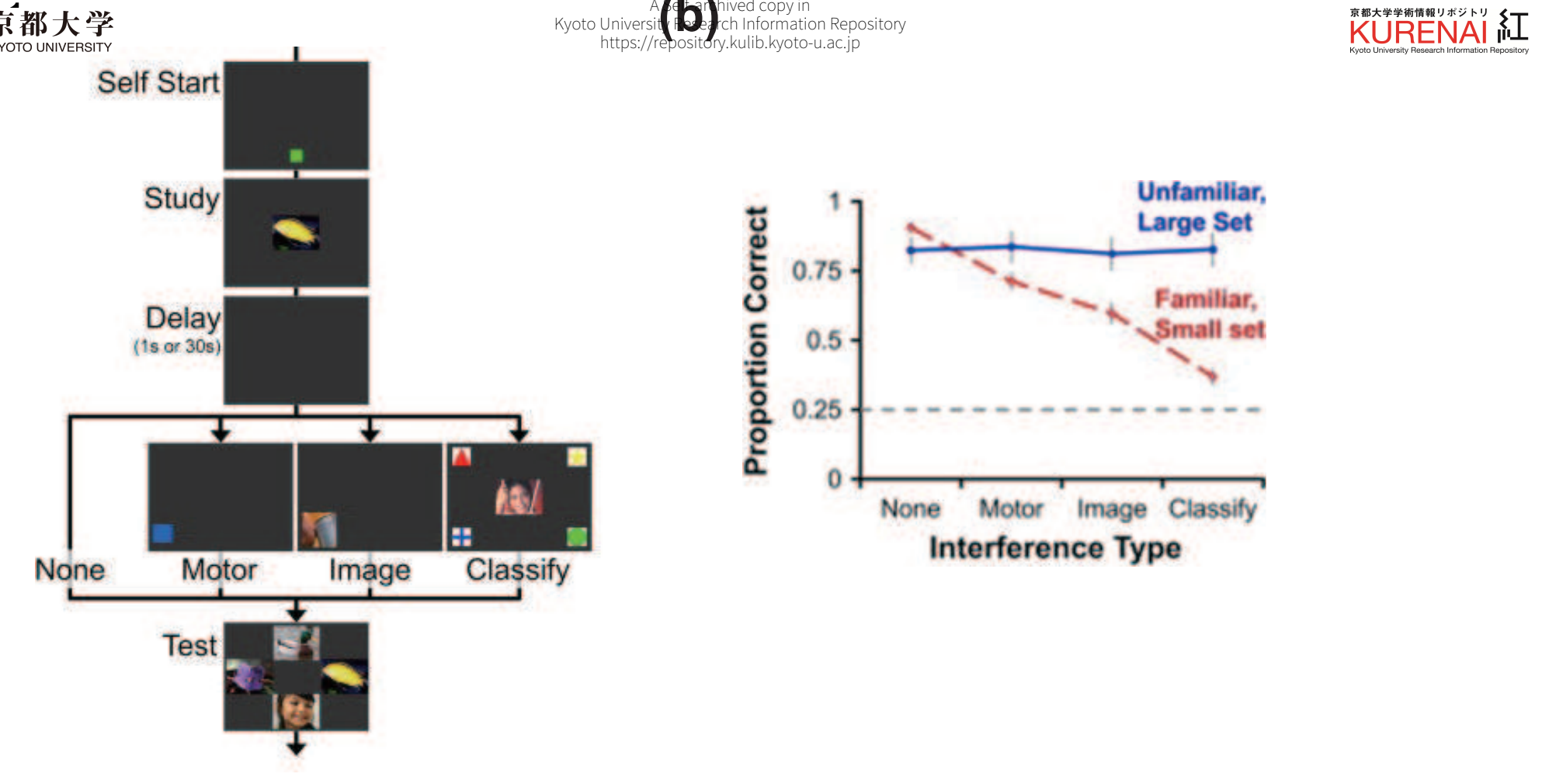

. 
(a)

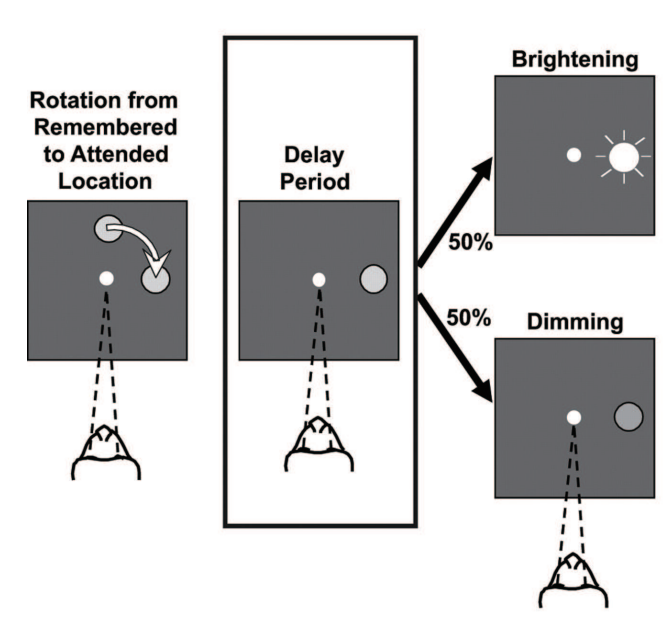

(b)
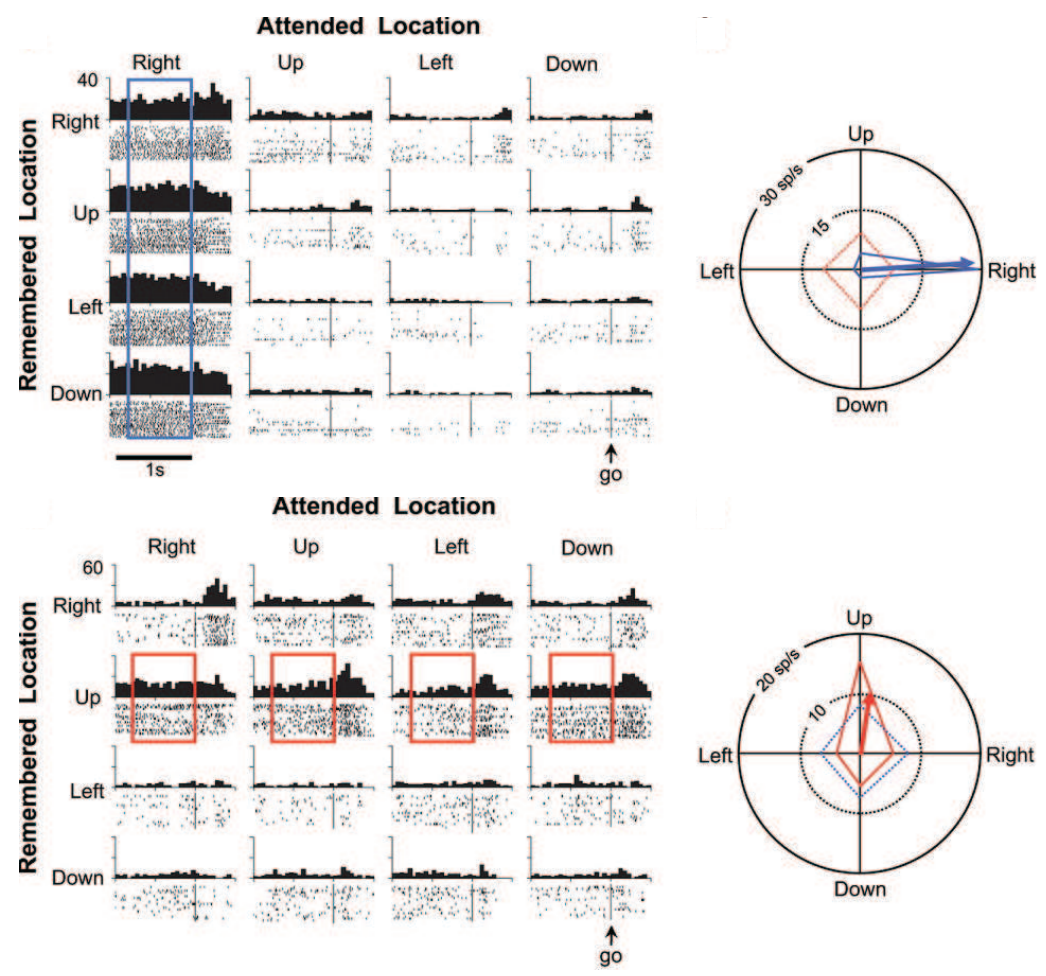

(d)
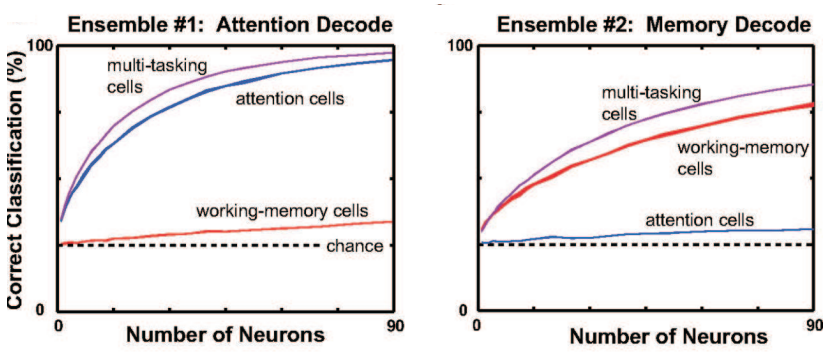

Saccade to

Remembered
Location

(c)
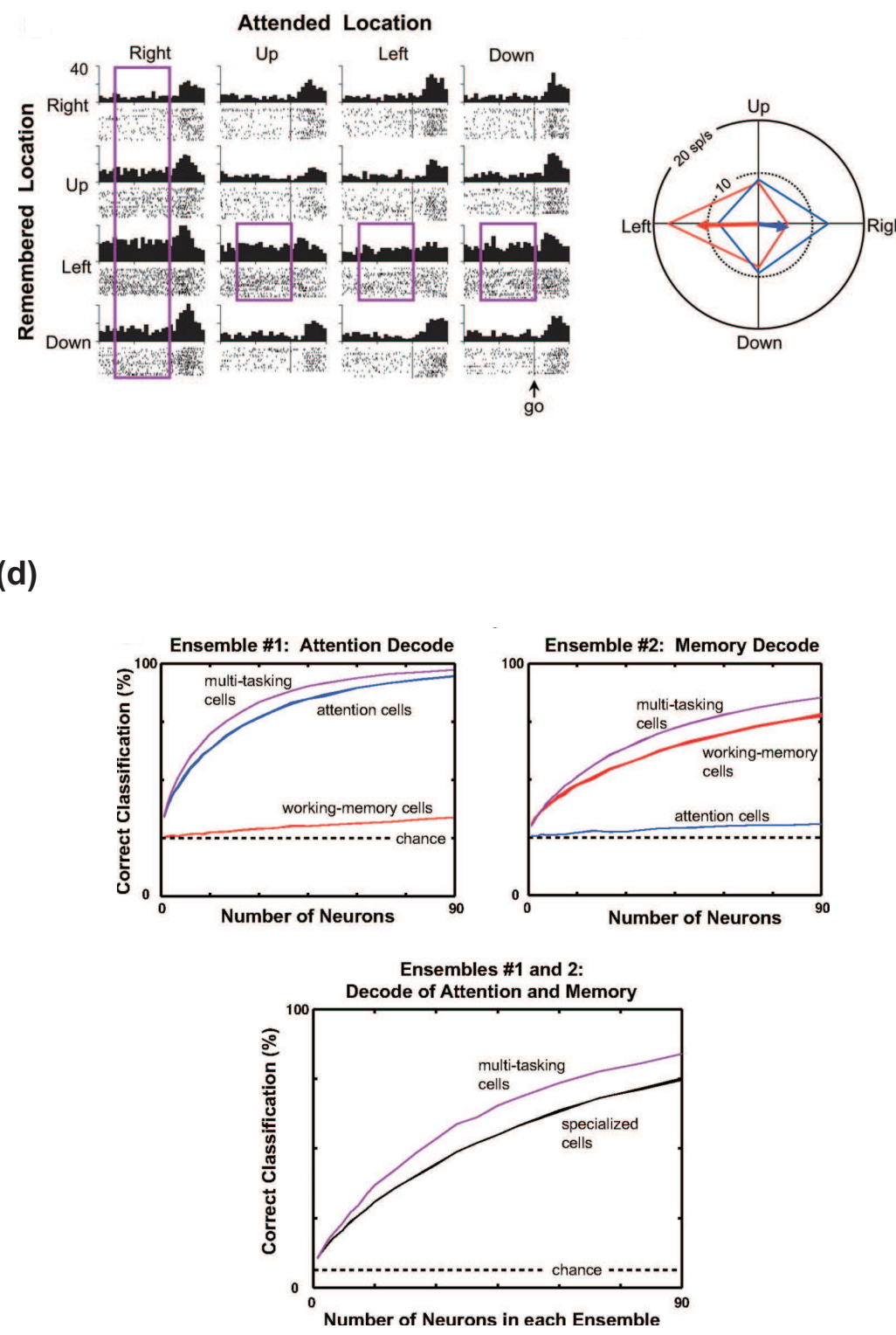


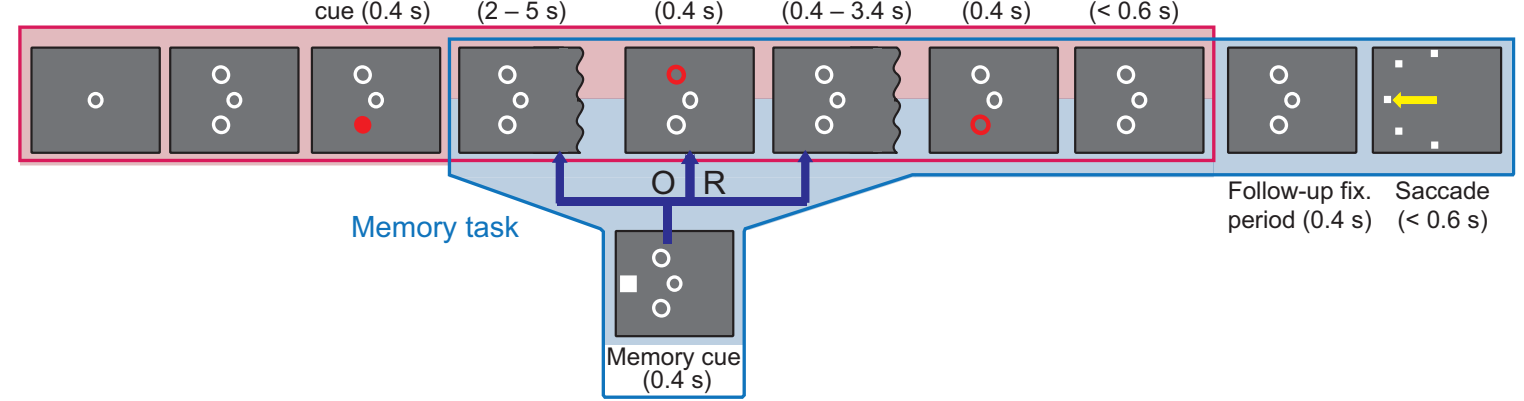

(b)

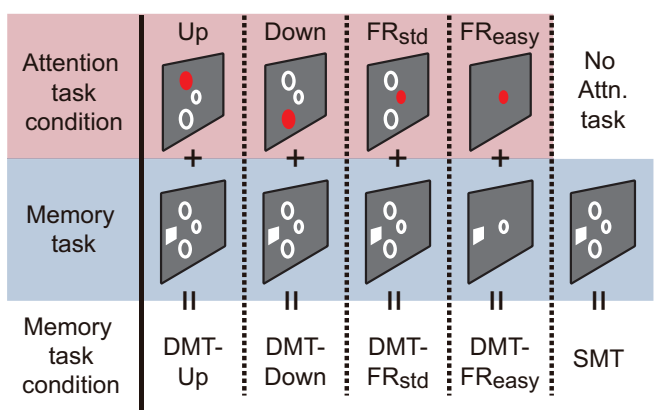

(d) (c)

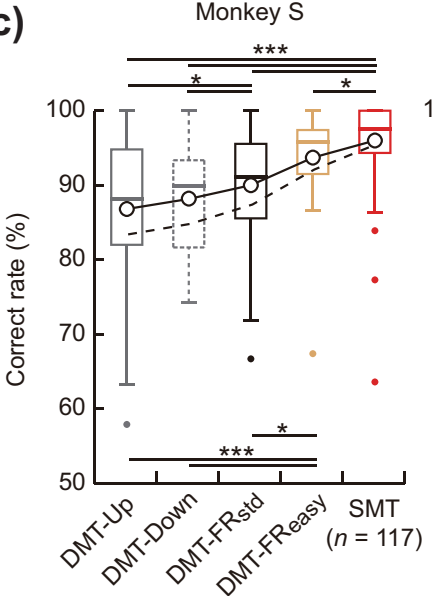

Monkey A

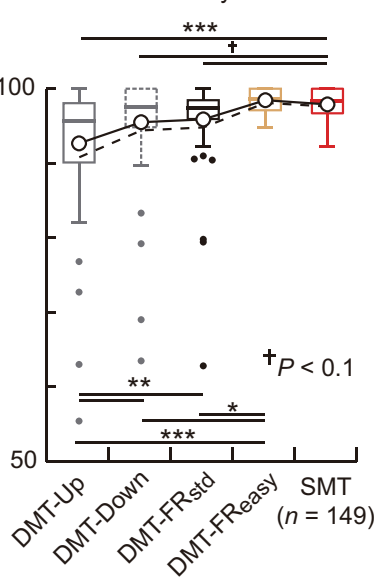

Memory task condition

DMT-FR std DMT-FReasy SMTpost
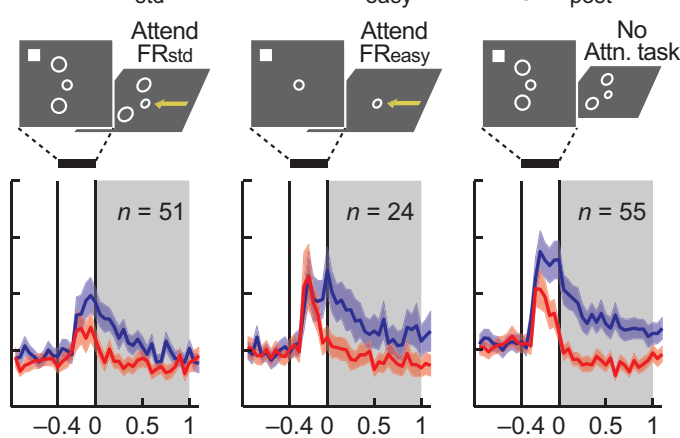

(e)

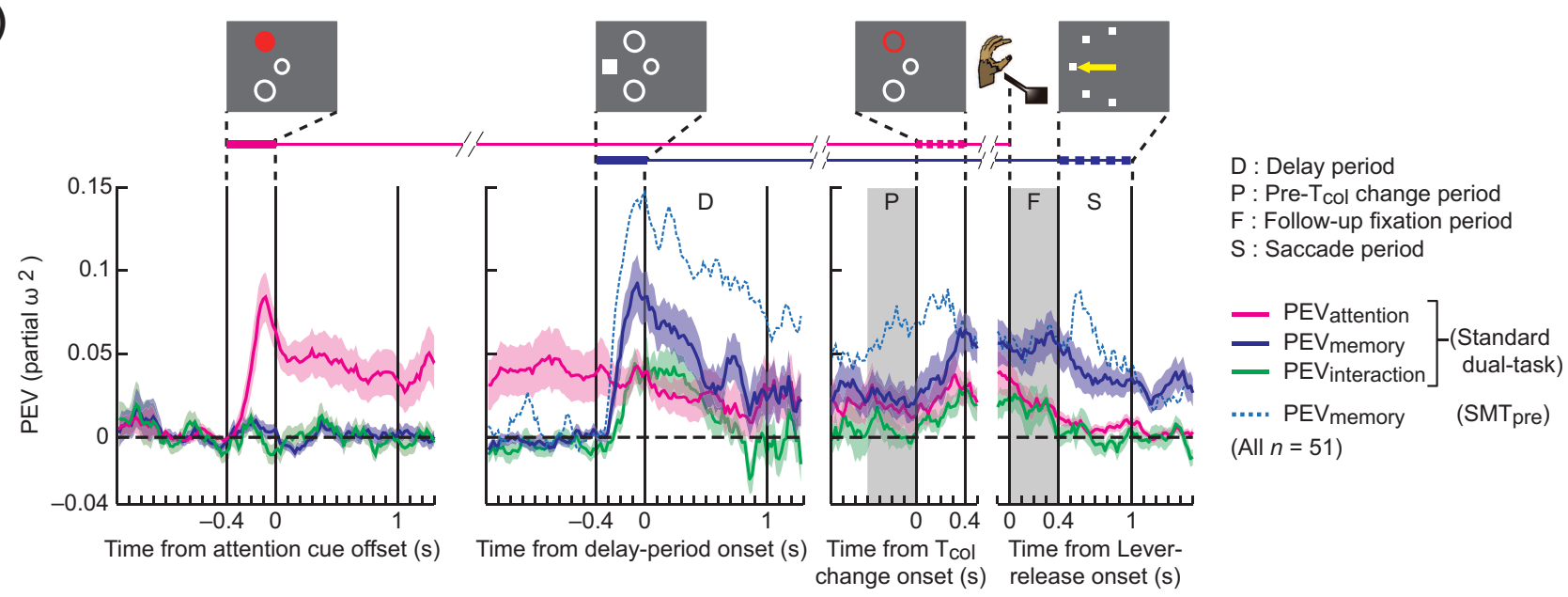


Table 1. Animal studies using dual-task paradigms

Species Combination of tasks

Behavioral studies

Moise [9]

Monke $\mathrm{DMS}^{\mathrm{a}}+$ simple reaction time task

Washburn and Astur [10]

y

Basile and Hampton [11]

$\mathrm{y}$

Smith et al. [12]

Monke

DMS + overt $\mathrm{OT}^{\mathrm{b}}$ or numerical judgment task

Monke

DMS + motor, image perception, or image classification $\mathrm{y}$ task

Monke DMS or $\mathrm{DMP}^{\mathrm{c}}+$ perceptual confidence judgment $\mathrm{y}$

Kendrick and Rilling [13]

Pigeon

$\mathrm{DMS}+\mathrm{VI}^{\mathrm{d}}, \mathrm{EXT}^{\mathrm{e}}$, or $\mathrm{DRO}^{\mathrm{f}}$ schedule

Calder and White [14]

Pigeon

DMS + VI schedule

Maki et al. [15]

Rat

8-arm $\mathrm{WS}^{\mathrm{g}}$ radial maze +4 -arm $\mathrm{WS}^{\mathrm{h}}$ radial maze

Beatty and Shavalia [16]

Rat

Roberts [17]

Rat

8-arm WS radial maze +8 -arm WS or WS radial maze

Cook and Brown [18]

Rat

Jarrard and Elmes [19]

Rat

Harper et al. [45]

Rat

8-arm WS radial maze +8 -arm WS radial maze

Neurophysiological studies

Lebedev et al. [30]

Monkey memory-guided saccade + luminance discrimination

Messinger et al. [31]

Monkey

memory-guided saccade + luminance discrimination

Miyazaki et al. [32]

Monkey memory-guided + visually-guided bimanual motor task.

Watanabe and Funahashi Monkey $\mathrm{DMP}+$ spatial attention task

[33]

\footnotetext{
${ }^{\mathrm{a}} \mathrm{DMS}=$ delayed matching-to-sample task

${ }^{\mathrm{b}} \mathrm{OT}=$ object tracking task

${ }^{\mathrm{c}} \mathrm{DMP}=$ delayed matching-to-place task

${ }^{\mathrm{d}} \mathrm{VI}=$ variable interval

${ }^{\mathrm{e}} \mathrm{EXT}=$ extinction

${ }^{\mathrm{f}} \mathrm{DRO}=$ differential reinforcement of other behavior
} 
${ }^{\mathrm{g}}$ In the WS (delayed spatial win-shift) radial maze task, animals are required to retain spatial information for visited arms both during task performance and across a delay. Optimal behavior consisits of visiting each arm without repetition.

${ }^{\mathrm{h}} \mathrm{WS}=$ spatial win-shift task

${ }^{\mathrm{i}} \mathrm{SPR}=$ serial probe recognition task 